\title{
Actinomyces hordeovulneris sp. nov., an Agent of Canine Actinomycosis
}

\author{
AUDRIA M. BUCHANAN, ${ }^{1 *}$ JAMON L. SCOTT, ${ }^{1,2}$ MARY ANN GERENCSER,${ }^{4}$ BLAINE L. BEAMAN,${ }^{3}$ SPENCER \\ $\mathrm{JANG}^{2}{ }^{2}$ AND ERNST L. BIBERSTEIN ${ }^{1}$
}

Department of Veterinary Microbiology and Immunology ${ }^{1}$ and Microbiology Diagnostic Laboratory, Veterinary Medicine Teaching Hospital, ${ }^{2}$ School of Veterinary Medicine and Department of Medical Microbiology and Immunology, School of Medicine, ${ }^{3}$ University of California, Davis, California 95616; and Department of Microbiology, West Virginia University, Morgantown, West Virginia $26506^{4}$

\begin{abstract}
Of 30 Actinomyces strains isolated from infections in dogs, 15 were found to have galactose, glucose, and rhamnose in their cell wall carbohydrates, whereas the remainder had only galactose and glucose. No 6deoxytalose was detected in any of our analyses. The biochemical characteristics of the rhamnose-positive strains deficient in 6-deoxytalose were similar to those of Actinomyces viscosus ATCC 19246 and ATCC 27045 , a reference dog strain. In contrast, the 15 strains having only galactose and glucose in their wall carbohydrates had biochemical and serological characteristics unlike those of any previously accepted species of Actinomyces. The name Actinomyces hordeovulneris sp. nov. is proposed for this organism which is associated with thoracic, abdominal, or recurrent localized infections that sometimes are associated with awns of foxtails (Hordeum spp). The type strain of A. hordeovulneris is strain ATCC 35275 (= UCD 81-332-9).
\end{abstract}

Strains of Actinomyces are agents of abscesses or systemic infections in dogs. In the western United States these infections are often associated with awns of several members of the grass genus Hordeum (commonly called foxtails) (3, 14; E. L. Biberstein and S. Jang, unpublished data). The disease is common in California, probably because of the moist winters, dry hot summers, and abundance of foxtails. Each awn resembles a miniature badminton bird with a sharp tip and flaring hairs; each hair has many barbs that prevent retrograde movement. As an animal moves through the wild grass, foxtail awns become trapped in its coat, or they may be inhaled or swallowed. The tips of the awns penetrate skin or mucous membranes and are propelled forward through the tissue with any adjacent muscle contractions. They leave trails of inflammation and necrosis. Actinomyces and other oral or gastrointestinal flora may be introduced directly when the animal licks or bites a wound, or they may spread hematogenously to this necrotic focus. The migrating awns can penetrate brains, body cavities, or spinal columns and can elicit life-threatening infections.

Actinomyces viscosus was reported to be an agent of actinomycosis in dogs by Georg et al. (9). In an earlier report, Brion (4) described similar filamentous organisms from canine lesions, but the physiological studies of these agents were incomplete and no reference strains are available for comparisons. Davenport et al. (6) reported the isolation $A$. viscosus from six dogs, two with empyemas and four with abscesses; none of the infections was indicated as being associated with grass awns.

In this study, cell wall composition $(2,8,15,16)$, biochemical activities in miniaturized systems $(19,20)$, and serological tests $(9,10,13,22)$ were used to identify 30 catalasepositive Actinomyces strains isolated from dogs. We describe the characteristics of a new agent, for which we propose the name Actinomyces hordeovulneris sp. nov. in

\footnotetext{
* Corresponding author.
}

recognition of its frequent clinical association with migrating foxtail awns.

\section{MATERIALS AND METHODS}

Strains. Hamster, human, and canine reference strains of A. viscosus (strains ATCC $15987^{\mathrm{T}}[\mathrm{T}=$ type strain $]$, ATCC 19246, and ATCC 27045) were obtained from the American Type Culture Collection, Rockville, Md., and were used for comparisons. The canine isolates were obtained during the last 4 years from 28 dogs treated at the University of California Veterinary Medicine Teaching Hospital. Older isolates were stored in skim milk at $-20^{\circ} \mathrm{C}$. Other organisms used as controls occasionally were Nocardia asteroides UCD 81-1-5 and Streptomyces griseus. All strains were maintained on Trypticase soy agar plates (Difco Laboratories, Detroit, Mich.) supplemented with $5 \%$ whole bovine blood and were transferred triweekly.

Oxygen requirements. The oxygen requirement of strain UCD 80-19-4 was determined at the Mycotic Diseases Division, Centers for Disease Control, by using the technique described by Slack (21). Plate cultures were incubated in candle extinction jars.

Analysis of whole cell carbohydrates. Cells were grown in two unvented $50-\mathrm{ml}$ blood culture bottles containing Trypticase soy broth with $\mathrm{CO}_{2}$ and without sodium polyanetholsulfonate (BBL Microbiology Systems, Cockeysville, Md.). The inoculum was a suspension of cells from a 48-h blood agar plate in $3 \mathrm{ml}$ of sterile fetal calf serum. The suspension was adjusted to a turbidity of a McFarland no. 3 or 4 tube, and $2.5 \mathrm{ml}$ was added to each $50-\mathrm{ml}$ unvented bottle with a syringe. After incubation at $37^{\circ} \mathrm{C}$ for 48 to $72 \mathrm{~h}, 0.5 \mathrm{ml}$ of $37 \%$ formaldehyde was added to each bottle. Then $18 \mathrm{~h}$ later, the cells were harvested by centrifugation at $3,000 \times g$ for 15 min and were washed twice with distilled water. The method of Staneck and Roberts (23) was used for analysis of whole cell carbohydrates, with the modifications described below. A 1-g portion of wet packed cells was acidified with $1.5 \mathrm{ml}$ of $1 \mathrm{~N} \mathrm{H}_{2} \mathrm{SO}_{4}$ and held in a sealed tube for $2 \mathrm{~h}$ in a boiling water 
bath. The $\mathrm{pH}$ of the hydrolysate was adjusted to 5.2 to 5.5 by dropwise addition of saturated barium hydroxide, and the precipitate was removed by centrifugation. The supernatant was evaporated to dryness, and the residue was dissolved in $0.3 \mathrm{ml}$ of distilled water. Samples were analyzed for carbohydrates by thin-layer chromatography as described by Staneck and Roberts (23), except that $3 \mu$ l was applied in 1$\mu l$ increments with intervening drying periods of $5 \mathrm{~min}$. In some experiments the amount spotted onto the chromatogram was increased to $6 \mu \mathrm{l}$. Sugar residues of some strains were also analyzed by gas-liquid chromatography as described previously by Beaman et al. (1).

Amino acid analysis of cell walls. Cell walls were partially purified from $0.5 \mathrm{~g}$ of packed wet cells by treatment with $10 \%$ trichloroacetic acid followed by treatment with trypsin, as described by Schleifer and Kandler (18), except that the suspension in trichloroacetic acid was adjusted to the turbidity of a McFarland no. 4 tube. The two-dimensional thinlayer chromatography method of Harper and Davis (11) was used with type 6064 Chromagram cellulose sheets (Eastman Kodak Co., Rochester, N.Y.) without fluorescent indicator and a thin-layer chromatography chamber (model 13259 Eastman Kodak Chromagram Developing Apparatus). Lysine, ornithine, aspartic acid, and diaminopimelic acid standards obtained from Sigma Chemical Co., St. Louis, Mo., were included in each analysis. Isopropanol-acetic acidwater $(75: 10: 15, \mathrm{vol} / \mathrm{vol})$ was used ascending, and methanolpyridine-10 $\mathrm{N}$ hydrochloric acid-water $(64: 8: 2: 14$, vol/vol) was used ascending in the second direction.

Biochemical tests. The tests for catalase and starch hydrolysis were performed by the technique described by Slack (21); the test for cytochrome oxidase activity was performed by the method of Deibel and Evans (7); and the tests for urease activity and nitrate reduction were performed as described by Schofield and Schaal (20). The carbohydrate fermentation tests were done by using the Schofield-Schaal modifications of the Minitek system $(19,20)$. Commercially available esculin disks (MiniTek) were inoculated at the same time. Fermentation products were determined by using the methods of Holdeman and Moore (12), except that we used a 3-ml samples of Trypticase soy broth cultures supplemented with $5 \%$ fetal calf serum instead of the recommended culture medium.

Serological studies. Fluorescein isothiocyanate-conjugated antisera specific for the following organisms were tested against strains UCD 80-19-4, UCD 81-154-4, and UCD 81345-981: A. viscosus serotype 1 strain WVU $745^{\mathrm{T}}$ (= ATCC $15987^{\mathrm{T}}$ ); A. viscosus serotype 2 strains WVU 371 (= ATCC 19246) and WVU 398B; Actinomyces israelii serotype 1 strains WVU 46 (= ATCC 12102), WVU 390, and WVU 30 (= ATCC 10048); A. israelii serotype 2 strain WVU 307 (= ATCC 29322); Actinomyces bovis serotypes 1 and 2; Actinomyces naeslundii serotypes 1,2 , and 3 ; Actinomyces odontolyticus serotypes 1 and 2; Actinomyces suis (Franke); Actinomyces pyogenes (formerly Corynebacterium pyogenes); Rothia dentocariosa serotypes 1, 2, and 3; and Rothia-like strain WVU 1556. Reactions at titers of 1:5, 1:10, 1:20, 1:40, and 1:80 were compared with homologous titers.

Antibiotic susceptibility. The minimal inhibitory concentrations of various antibiotics were determined by the agar dilution technique, using 72-h cultures in mycoplasma broth (without inhibitors; Difco) supplemented with 5\% fetal calf serum and $5 \%$ yeast extract (freshly prepared from a $25 \%$ aqueous slurry of active dry yeast) adjusted to the turbidity of a McFarland no. 0.5 tube as inocula and Mueller-Hinton agar plates supplemented with $5 \%$ fetal calf serum as the test medium. The minimal inhibitory concentrations were compared with the minimal inhibitory concentrations for Staphylococcus aureus ATCC 29213, Streptococcus faecalis ATCC 29212, Escherichia coli ATCC 25922, and Pseudomonas aeruginos $a$ and were corrected for the influence of $\mathrm{CO}_{2}$ on the test.

DNA isolation and determination of base contents. Deoxyribonucleic acids (DNAs) of $A$. viscosus ATCC $15987^{\mathrm{T}}$ and strain UCD $81-332-9^{\mathrm{T}}$ were isolated by a procedure generously shared with us before publication (I. Yu et al., manuscript in preparation). Briefly, all solutions, glass, and plastic ware were sterilized. Cells were grown for $24 \mathrm{~h}$ in 1 liter of brain heart infusion broth supplemented with $5 \%$ fetal calf serum. After $2 \mathrm{ml}$ of diethylpyrocarbonate (CalbiochemBehring, La Jolla, Calif.) was added, the cells were harvested by centrifugation, washed with $0.02 \mathrm{M}$ 2-amino-2-(hydroxymethyl)-1,3-propanediol buffer ( $\mathrm{pH}$ 7.8) containing $0.01 \mathrm{M}$ ethylenediaminetetraacetic acid and $0.44 \mathrm{M}$ sucrose (sucrose buffer), and suspended in $10 \mathrm{ml}$ of $1 \%$ Sarkosylsucrose buffer. The cells were mixed with an equal volume of acid-cleaned and neutralized glass beads (diameter, 0.45 $\mathrm{mm}$ ) and shaken for 5 min under intermittant $\mathrm{CO}_{2}$ in a homogenizer (Braun, Melsungen, Federal Republic of Germany). The suspension was decanted and combined with one washing of the glass beads with $1 \%$ Sarkosyl-sucrose buffer. Sodium perchlorate and $30 \%$ Sarkosyl-sucrose buffer were added to final concentrations of $1 \mathrm{M}$ and $1 \%$, respectively, The DNA was deproteinized once with chloroformisoamyl alcohol $(24: 1)$, precipitated overnight in 3 volumes of absolute ethanol, and harvested by centrifugation at 7,700 $\times g$. The pellet was dissolved in $0.15 \mathrm{M} \mathrm{NaCl}-0.15 \mathrm{M}$ trisodium citrate $(\mathrm{pH} 7.0 \pm 0.2)$ and treated for $6 \mathrm{~h}$ at $25^{\circ} \mathrm{C}$ with $100 \mu \mathrm{g}$ of amylase derived from Bacillus licheniformis per $\mathrm{ml}$ and $100 \mu \mathrm{g}$ of ribonuclease (type XIIA; nuclease-free) per $\mathrm{ml}$, both previously heated at $90^{\circ} \mathrm{C}$; this was followed by treatment with $100 \mu \mathrm{g}$ of proteinase K (type XI; Sigma) per $\mathrm{ml}$ for $4 \mathrm{~h}$ at room temperature. The DNA was deproteinized a second time with chloroform-isoamyl alcohol, precipitated with ethanol as described above, collected by centrifugation, and dissolved in $0.003 \mathrm{M}$ sodium phosphate buffer. DNA base contents (guanine-plus-cytosine contents) were determined from the buoyant densities in cesium chloride gradients by the method of Schildkraut et al. (17). Micrococcus lysodeikticus and $E$. coli $\mathrm{K}-12$ DNAs were used as internal standards for the gradients.

\section{RESULTS AND DISCUSSION}

Physiological characters have been used for many years to identify members of the Actinomycetaceae; however, the recommended carbohydrate fermentation (21) and end product analysis (12) tests were not applicable with the canine strains due to inadequate growth. The modified Minitek procedures described by Schofield and Schaal $(19,20)$ gave reproducible results in repeated tests. Some investigators consider carbohydrate fermentation tests of limited value in the delineation of species except when a large battery of tests is performed (16). Nevertheless, the high degree of correlation which we observed among the cell wall carbohydrates, colony type, and fermentation pattern of each dog isolate suggests otherwise.

A total of 15 isolates and reference strain ATCC 27045 lacked 6-deoxytalose in their cell wall carbohydrates, but had other cell wall and biochemical characteristics similar to those of $A$. viscosus ATCC 19246. The absence of 6deoxytalose was inferred by comparisons with chromatograms obtained from A. viscosus ATCC $15987^{\mathrm{T}}$ and ATCC 

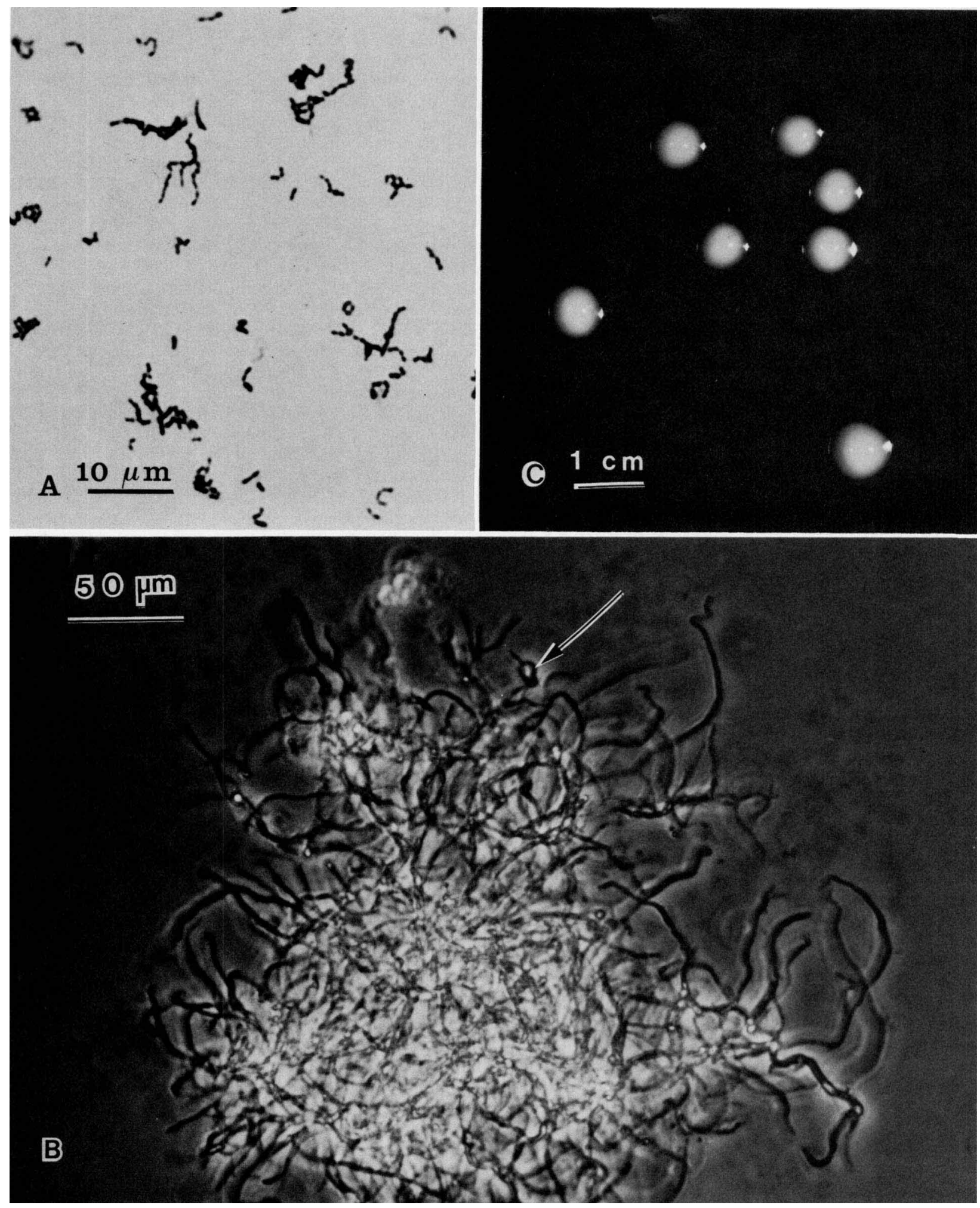

FIG. 1. (A) Morphology of strain UCD 81-332-9 $9^{\mathrm{T}}$ cells in Gram stains prepared from $48-\mathrm{h}$ blood agar cultures. $\times 1,340$. (B) Strain UCD 81 $332-9^{\mathrm{T}}$ cells grown for $48 \mathrm{~h}$ in brain heart infusion broth supplemented with $15 \%$ fetal calf serum. Diphtheroid cells were observed infrequently. The arrow indicates a swollen filament terminus where spheroplast-like bodies occasionally develop. $\times 162$. (C) Colonies of strain UCD $81-332-9^{\mathrm{T}}$ grown for $48 \mathrm{~h}$ on $5 \%$ bovine blood agar plates. $\times 12.5$. 
19246 and probably accounts for the one-way cross-reaction observed by Georg et al. (9) between strain ATCC 19246 antisera and strain ATCC 27045 (A1231) antigen. Infections containing this kind of $A$. viscosus were usually of a localized nature and responded well to ampicillin administration.

The remaining 15 isolates lacked rhamnose and 6-deoxytalose in their cell wall carbohydrates and had biochemical and serological characteristics that were distinct from those of previously described species of Actinomyces. For these strains we propose the name Actinomyces hordeovulneris sp. nov. (hor. de. o. vul' ne. ris. L. n. Hordeum genus of grass; L. n. vulnus wound, injury; N. L. adj, hordeovulneris Hordeum injury). A description of this new species is given below.

Actinomyces hordeovulneris sp. nov. Cells are pleomorphic rods and filaments that are 0.5 to $1.0 \mu \mathrm{m}$ in diameter and usually exhibit a noticeable degree of branching on blood agar (Fig. 1A). In broth supplemented with $15 \%$ fetal calf serum, the filaments are long and extensively branched and have swollen termini (Fig. 1B), where spheroplast-like bodies occasionally develop (data not shown). Dissociation to diphtheroid cells is incomplete in broth cultures.

Surface colonies on bovine blood agar are white, agar adherent, and molar toothed (data not shown, but similar to $A$. israelii [16]), with a tendency to shift to a white, conical, domed, buttery, less adherent type (Fig. 1C) upon laboratory passage. Diameters are 0.5 to $1.0 \mathrm{~mm}$ after $48 \mathrm{~h}$ at $37^{\circ} \mathrm{C}$ and 2 $\mathrm{mm}$ after 3 days. On clear media (Trypticase soy or brain heart infusion agar plates supplemented with 10 to $20 \%$ fetal calf serum) microcolonies after $24 \mathrm{~h}$ of incubation at $37^{\circ} \mathrm{C}$ are regularly filamentous and similar to those of $A$. israelii (16). Young colonies are more white and raised and have smaller diameters than those of the 6-deoxytalose-negative $A$. viscosus strains isolated from dogs.

Growth is weak in unvented or vented Trypticase soy broth cultures unless they are supplemented with serum; it is flocculant with $\geq 5 \%$ fetal calf serum. All strains are facultatively anaerobic, but require $\mathrm{CO}_{2}$ for growth. Acetic acid, lactic acid, and major amounts of succinic acid are detectable upon analysis of 3-ml samples withdrawn from Trypticase soy broth cultures supplemented with $5 \%$ fetal calf serum. All strains have weak to moderate catalase activity and are negative in the benzidine test (7). Most strains, including the type strain, are nonhemolytic on bovine blood agar, but a few exhibit weak activity which becomes noticeable after 7 days. Acetylmethyl carbinol and urease are not produced, and nitrates are not reduced. Esculin is hydrolyzed.

All strains produce acid from cellobiose, glucose, lactose, maltose, trehalose, and xylose. Acid is produced from mannose, melibiose, and raffinose, but production is weak by some strains other than the type strain. All strains fail to produce acid from arabinose, glycerol, mannitol, mesoinositol, rhamnose, and ribose.

Peptidoglycans of all strains contain lysine, alanine, and glutamic acid. Ornithine is present in the walls of most strains. The wall carbohydrates include glucose and galactose. Rhamnose and 6-deoxytalose are absent.

As shown in Table 1, all three strains tested cross-reacted with antisera against $A$. israelii serotype 1 strain ATCC 12102 and $A$. viscosus serotype 1 strain ATCC $15987^{\mathrm{T}}$ but in titers much lower than homologous levels. The reactions of these dog strains with $A$. israelii serotype 1 antisera exceeded those with $A$. viscosus ATCC $15987^{\mathrm{T}}$. No serological reactions were observed with antisera against $A$. viscosus serotype 2 strain ATCC 19246, A. israelii serotype 2 strain ATCC 29322, A. bovis serotypes 1 and $2, A$. naeslundii serotypes 1,2 , and 3, A. odontolyticus serotypes 1 and $2, A$. suis, $A$. pyogenes (formerly $C$. pyogenes), $R$. dentocariosa serotypes 1,2, and 3, and Rothia-like strain WVU 1556.

Five of five $A$. hordeovulneris strains tested were susceptible to $\leq 0.25 \mu \mathrm{g}$ of penicillin $\mathrm{G}$ per $\mathrm{ml}$ and $\leq 0.25 \mu \mathrm{g}$ of cephalothin per $\mathrm{ml}$, and all were inhibited by $1 \mu \mathrm{g}$ of chloramphenicol per $\mathrm{ml}$ and $1 \mu \mathrm{g}$ of trimethoprim sulfa per ml. Strain UCD 81-332-9 ${ }^{\mathrm{T}}$ had a tetracycline minimal inhibitory concentration of $4 \mu \mathrm{g} / \mathrm{ml}$, whereas the other four strains tested were susceptible to 0.5 or $1.0 \mu \mathrm{g}$ of tetracycline per $\mathrm{ml}$.

The A. hordeovulneris strains were isolated from cases of pleuritis, peritonitis, visceral abscesses, septic arthritis, and recurrent localized infections often occurring secondary to tissue-wandering foxtailawns. Three animals died despite ampicillin treatment. A second drug, usually tribrissen, was added to or substituted for ampicillin to achieve favorable responses in other cases due to $A$. hordeovulneris. Occasionally, $A$. viscosus and $A$. hordeovulneris were present in the same sample. The unfavorable responses to ampicillin may be related to a marked tendency to produce L-forms spontaneously with coincident uptake of calcium (A. M. Buchanan and J. L. Scott, submitted for publication).

The guanine-plus-cytosine content of the DNA of $A$. hordeovulneris UCD $81-332-9^{\mathrm{T}}\left(=\right.$ ATCC $\left.35275^{\mathrm{T}}\right)$ was 67 mol\%, compared with $69 \mathrm{~mol} \%$ for $A$. viscosus ATCC $15987^{\mathrm{T}}$. This value for strain ATCC $15987^{\mathrm{T}}$ is in agreement with the data of Coykendall and Munzenmaier (5), whose calculation was based on the thermal denaturation temperature.

Strain ATCC 35275 (= UCD 81-332-9) is the type strain of

TABLE 1. Fluorescent antibody reactions of canine strains with $A$. israelii and $A$. viscosus antisera

\begin{tabular}{|c|c|c|c|c|}
\hline \multirow{2}{*}{ Antiserum $^{a}$} & \multicolumn{3}{|c|}{ Titer against strain: } & \multirow{2}{*}{ Homologous titer ${ }^{b}$} \\
\hline & UCD 80-19-4 & UCD 81-154-4 & UCD 81-345-981 & \\
\hline \multicolumn{5}{|l|}{ A. israelii serotype 1 strains } \\
\hline WVU $46(=$ ATCC 12103) & $1: 40$ & $1: 40$ & $1: 40$ & $1: 640$ \\
\hline WVU 390 & $1: 20$ & $<1: 20$ & $1: 20$ & $1: 160$ \\
\hline WVU 30 (= ATCC 10048) & $<1: 20$ & $1: 20$ & $<1: 20$ & $1: 320$ \\
\hline A. israelii serotype 2 strain WVU 307 (= ATCC 29322) & $<1: 640$ & $<1: 640$ & $<1: 640$ & $1: 1,280$ \\
\hline A. viscosus serotype 1 strain WVU $745^{\mathrm{T}}\left(=\right.$ ATCC $\left.15987^{\mathrm{T}}\right)$ (hamster) & $1: 10$ & $<1: 5$ & $1: 5$ & $1: 80$ \\
\hline \multicolumn{5}{|l|}{ A. viscosus serotype 2 strains } \\
\hline WVU 371 (= ATCC 19246) (human) & $<1: 10$ & $<1: 10$ & $<1: 10$ & $1: 40$ \\
\hline WVU 398B (human) & $<1: 10$ & $<1: 10$ & $<1: 10$ & $1: 160$ \\
\hline
\end{tabular}

${ }^{a}$ Fluorescein-to-protein ratios for antisera to strains $A$. israelii WVU 46 and WVU 307 were 11 and $13 \mu \mathrm{g} / \mathrm{mg}$, respectively; ratios for $A$. israelii WVU 30 and WVU 390 were not available. The values for antisera to $A$. viscosus WVU $745^{\mathrm{T}}$, WVU 371 , and WVU $398 \mathrm{~B}$ were 36,22 , and $24 \mu \mathrm{g} / \mathrm{mg}$, respectively.

${ }^{b}$ Homologous titers of the antisera with $A$. israelii and $A$. viscosus cells. 
TABLE 2. Characteristics useful for distinguishing $A$. hordeovulneris from other fermentative actinomycetes ${ }^{a}$

\begin{tabular}{|c|c|c|c|c|c|c|c|c|}
\hline \multirow{2}{*}{ Taxon } & \multirow{2}{*}{ Catalase } & \multirow{2}{*}{$\begin{array}{c}\mathrm{NO}^{3} \\
\text { reduction }\end{array}$} & \multicolumn{6}{|c|}{ Acid produced from: } \\
\hline & & & Cellobiose & Glycerol & $m$-Inositol & Ribose & Trehalose & Xylose \\
\hline A. hordeovulneris & $100^{b}$ & 0 & 100 & 0 & 0 & 0 & 100 & 100 \\
\hline A. viscosus ATCC $15987^{\mathrm{T}}$ & + & + & - & + & + & - & - & - \\
\hline A. viscosus АТCC 19246 & + & + & - & - & + & + & + & - \\
\hline A. viscosus dog strains ${ }^{c}$ & 100 & 100 & 0 & 100 & 100 & 100 & 100 & 0 \\
\hline A. israelii & 0 & 59 & 87 & 8 & 91 & 100 & 83 & 93 \\
\hline A. naeslundii & 0 & 100 & 35 & 18 & 94 & 35 & 100 & 35 \\
\hline R. dentocariosa & 100 & 100 & 0 & 14 & 0 & $\mathbf{0}$ & 0 & 35 \\
\hline Bacterionema matruchotii & 100 & 100 & $\mathbf{0}$ & 0 & 0 & 78 & 0 & 0 \\
\hline
\end{tabular}

${ }^{a}$ The characteristics of $A$. hordeovulneris, A. viscosus ATCC $15987^{\mathrm{T}}$ and ATCC 19246, and the 6-deoxytalose-negative $A$. viscosus strains isolated from dogs are based on data obtained in this study. The data of Schofield and Schaal $(18,19)$ were used for $A$. israelii, A. naeslundii, $R$. dentocariosa, and Bacterionema matruchotii.

${ }^{b}$ The values are (number of strains positive divided by number tested) $\times 100$.

c These strains were the rhamnose-positive, 6-deoxytalose-negative strains identified in this study as $A$. viscosus and $A$. viscosus strain ATCC 27045.

A. hordeovulneris. Characteristics that are useful in distinguishing this new Actinomyces species from other fermentative actinomycetes are given in Table 2 .

\section{ACKNOWLEDGMENTS}

This investigation was supported in part by Public Health Service grants BRSG 81-26 and BRSG 82-12 from the National Institutes of Health and by companion animal research funds privately donated to the School of Veterinary Medicine, University of California, Davis.

\section{LITERATURE CITED}

1. Beaman, B. L., A. L. Bourgeois, and S. E. Moring. 1981. Cell wall modification resulting from in vitro induction of $L$-phase variants of Nocardia asteroides. J. Bacteriol. 148:600-609.

2. Boone, C. J., and L. Pine. 1968. Rapid method for characterization of Actinomycetes by cell wall composition. Appl. Microbiol. 16:279-284.

3. Brennan, K. E., and P. J. Ihrke. 1983. Grass awn migration in dogs and cats: a retrospective study of 182 cases. J. Am. Vet. Med. Assoc. 182:1201-1204

4. Brion, A. 1939. L'actinomycose du chien et du chat. Rev. Med. Vet (Lyon) 91:121-159.

5. Coykendall, A. L., and A. J. Munzenmaier. 1979. Deoxyribonucleic acid hybridization among strains of Actinomyces viscosus and Actinomyces naeslundii. Int. J. Syst. Bacteriol. 29:234-240.

6. Davenport, A. A., G. R. Carter, and R. G. Schirmer. 1974. Canine actinomycosis due to Actinomyces viscosus: report of six cases. Vet. Med. Small Anim. Clin. 69:1442-1447.

7. Deibel, R. H., and J. B. Evans. 1960. Modified benzidine test for the detection of cytochrome-containing respiratory systems in microorganisms. J. Bacteriol. 79:356-360.

8. DeWeese, M. S., M. A. Gerencser, and J. M. Slack. 1968. Quantitative analysis of Actinomyces cell walls. Appl. Microbiol. 16:1713-1718.

9. Georg, L. K., J. M. Brown, H. J. Baker, and G. H. Cassell. 1972. Actinomyces viscosus as an agent of actinomycosis in the dog. Am. J. Vet. Res. 33:1457-1470.

10. Gerencser, M. A., and J. M. Slack. 1969. Identification of human strains of Actinomyces viscosus. Appl. Microbiol. 18:80-87.
11. Harper, J. J., and G. H. G. Davis. 1979. Two-dimensional thinlayer chromatography for amino acid analysis of bacterial cell walls. Int. J. Syst. Bacteriol. 29:56-58.

12. Holdeman, L. V., and W. E. C. Moore. 1972. Anaerobe laboratory manual. Virginia Polytechnic Institute and State University Anaerobe Laboratory, Blacksburg.

13. Holmberg, K., and U. Forsum. 1973. Identification of Actinomyces, Arachnia, Bacterionema, Rothia, and Propionibacterium species by defined immunofluorescence. Appl. Microbiol. 25:834-843.

14. Hur, D. E. 1974. Foxtail foreign bodies in dogs and cats. Mod. Vet. Pract. 55:29-31.

15. Johnson, J. L., and C. S. Cummins. 1972. Cell wall composition and deoxyribonucleic acid similarities among the anaerobic coryneforms, classical propionibacteria, and strains of Arachnia propionica. J. Bacteriol. 109:1047-1066.

16. Schaal, K. P., and G. Pulverer. 1981. The genera Actinomyces, Agromyces, Arachnia, Bacterionema, and Rothia, p. 19231950. In M. P. Starr, H. Stolp, H. G. Trüper, A. Balows, and H. G. Schlegel (ed.), The prokaryotes, vol. 2. Springer-Verlag, Berlin.

17. Schildkraut, C. L., J. Marmur, and P. Doty. 1962. Determination of the base composition of deoxyribonucleic acid from its buoyant density in CsCl. J. Mol. Biol. 4:430-433.

18. Schleifer, K. H., and O. Kandler. 1972. Peptidoglycan types of bacterial cell walls and their taxonomic implication. Bacteriol. Rev. 36:407-477.

19. Schofield, G. M., and K. P. Schaal. 1980. Carbohydrate fermentation patterns of facultatively anaerobic actinomycetes using micro-methods. FEMS Lett. 8:67-69.

20. Schofield, G. M., and K. P. Schaal. 1981. A numerical taxonomic study of members of the Actinomycetaceae and related taxa. J. Gen. Microbiol. 127:237-259.

21. Slack, J. M. 1968. Subgroup of taxonomy of microaerophilic actinomycetes. Report on organization, aims, and procedures. Int. J. Syst. Bacteriol. 18:253-262.

22. Slack, J. M., S. Landfried, and M. A. Gerencser. 1971. Identification of Actinomyces and related bacteria in dental calculus by the fluorescent antibody technique. J. Dent. Res. 50:78-82.

23. Staneck, J. L., and G. D. Roberts. 1974. Simplified approach to identification of aerobic actinomycetes by thin-layer chromatography. Appl. Microbiol. 28:226-231. 